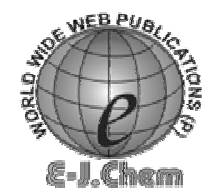

http://www.e-journals.net
ISSN: 0973-4945; CODEN ECJHAO

E-Journal of Chemistry

Vol. 5, No. 2, pp.291-301, April 2008

\title{
Preparation and Analytical Properties of Amphoteric Chelating Resin
}

\author{
BHAVNA A SHAH*, AJAY V SHAH ${ }^{\#}$ and PATHIK M SHAH \\ Department of Chemistry, Veer Narmad South Gujarat University, Surat, India. \\ ${ }^{\#}$ Science and Humanity Department, Polytechnic, \\ Vidhyabharati Trust, Umarakh, Bardoli. India. \\ bhavna606@yahoo.co.in
}

Received 5 October 2007; Accepted 3 December 2007

\begin{abstract}
The chelating ion exchange resin AFM was synthesized by condensation of anthranilic acid with formaldehyde and $m$-cresol in DMF media at $100{ }^{\circ} \mathrm{C} \pm 6{ }^{\circ} \mathrm{C}$. The identification of resin structure was performed by elemental and FTIR analysis. The thermodynamic parameters such as activation energy $\left(E_{a}\right)$, entropy $\left(S^{*}\right)$, enthalpy $\left(H^{*}\right)$ and free energy $\left(G^{*}\right)$ for thermal decomposition were calculated from thermal data. The morphology of AFM resin shows transition material between crystalline and amorphous phase. The rate of exchange was rapid. i.e. $\mathrm{t}_{1 / 2}<22 \min$ for $\mathrm{Pb}(\mathrm{II})$ and $\mathrm{pH}$ dependence of exchange of metal ions on the resin has been determined for several metal ions [ $\mathrm{Ni}(\mathrm{II}), \mathrm{Cu}(\mathrm{II}), \mathrm{Zn}(\mathrm{II}), \mathrm{Cd}(\mathrm{II})$ and $\mathrm{Pb}(\mathrm{II})]$. Successive separations and recovery of some pair of metal ions $[\mathrm{Pb}(\mathrm{II})-\mathrm{Cd}(\mathrm{II}), \mathrm{Pb}$ (II)$\mathrm{Zn}(\mathrm{II})$ and $\mathrm{Zn}(\mathrm{II})-\mathrm{Cu}(\mathrm{II})]$ have been performed by using distribution coefficient $\left(\mathrm{K}_{\mathrm{d}}\right)$.
\end{abstract}

Keywords: Free Energy, Crystalline-Amorphous, Distribution coefficient $\left(\mathrm{K}_{\mathrm{d}}\right)$, Ion Exchange Capacity, Binary Mixture.

\section{Introduction}

Despite advances in instrumentation and processor technologies, the determination of trace elements in complex matrices remains to be one of the most challenging areas of analytical chemistry. Chelating ion chromatography is considered as a very powerful technique for trace and ultra trace ion analyses in complex matrices ${ }^{1}$. The presence of heavy metals in environment is a cause of concern due to their acute and long-term toxicity. Cadmium and mercury are the major hazardous metals present in the environmental wastewater. Thus, removal of trace heavy metals from the environmental area have become of increasing 
interest and there is a strong need for a reliable analytical procedure that can be applied for the removal and determination of these metals at very low concentrations ${ }^{2}$. Since long, considerable interest has been developed in the synthesis of ion exchange resin having selective properties and containing selective functional groups.

Lutfor $e t a l^{3}$ prepared a chelating ion exchange resin containing amidoxime functional group. The chelating poly (amidoxime) resin was characterized by FTIR spectra, TG and DSC analyses. The chelating behavior of the prepared resin was studied with $\mathrm{Cu}$ (II), $\mathrm{Zn}$ (II), $\mathrm{Ni}(\mathrm{II}), \mathrm{Cd}(\mathrm{II})$ and $\mathrm{Pb}(\mathrm{II})$ metal ions. Samir et $a l^{4}$ synthesized ion exchange resin from 8-quinolinyl methacrylate and characterized by conventional methods. The thermal analysis was carried out using TGA and DSC. The metal ion uptake capacities of synthesized copolymers were estimated by batch equilibration method using different metal ion solutions under different experimental conditions.

Three phenol-formaldehyde chelating resins, poly (8-hydroxy quinoline-5, 7 diylmethylene), poly (8-hydroxy quinoldine-5, 7 diylmethylene) and poly (2-amino phenol5, 7 diylmethylene) were synthesized and characterized by Ebraheem ${ }^{5}$. The chelating characteristics of these polymers were studied by a batch equilibrium technique. The ion exchange capacity, effect of electrolyte on metal ion up take, rate of metal uptake and distribution of metal ion at different $\mathrm{pH}$ with resin copolymer derived from thiosemicarbazone derivatives of phenolic compound shows higher order than the resin copolymer derived from semicarbazone derivatives ${ }^{6}$. Recently much work has been carried out to study the ion exchange properties of anchoring functional chelating groups on the polymeric network. But as compared to anchored resins, the synthesized resins are more advantageous because the synthesized insoluble functionalized polymer can provide good stability and good flexibility in working conditions.

The purpose of the present work is to explore the possibility of separation of $\mathrm{Pb}(\mathrm{II})$ ion from matrices by using AFM chelating resin. The sorption behavior of $\mathrm{Ni}(\mathrm{II}), \quad \mathrm{Cu}(\mathrm{II})$, $\mathrm{Zn}(\mathrm{II}), \mathrm{Cd}(\mathrm{II})$ and $\mathrm{Pb}(\mathrm{II})$ on this resin was investigated at different $\mathrm{pH}$ values and at its different concentrations. The quantitative separations of $\mathrm{Pb}(\mathrm{II})-\mathrm{Cd}(\mathrm{II}), \mathrm{Pb}$ (II)- $\mathrm{Zn}$ (II) and $\mathrm{Zn}$ (II)-Cu(II) mixtures were achieved by the columns of the chelating resin. The separations are based on the affinity differences of these metal ions towards the chelating resin as a function of $\mathrm{pH}$ and tartaric acid electrolyte concentrations.

\section{Experimental}

\section{Materials}

All the reagents are of Analytical Grade and their purity were more than $98 \%$. Anthranilic acid: (Loba Chem., Mumbai) purified by rectified spirit. Formaldehyde (37\% w/v): (S.D. Fine Chem., Ltd. Mumbai.) was used as received. $m$-cresol: (Loba Chem., Mumbai) purified by distillation. Metal ion solutions were prepared by dissolving appropriate amount of metal acetates in double distilled water and standardized by complexometric titration.

\section{Preparation of the AFM Resin}

Anthranilic acid $(13.7 \mathrm{~g}, 0.1$ mole) was ground to fine powder and was taken in to a 250 $\mathrm{mL}$ four-necked flask. It was fitted with a condenser, thermometer, stirrer and addition funnel containing $20 \mathrm{~mL}$ of DMF, which was added dropwise at room temperature. After the addition of DMF, $37 \% \mathrm{w} / \mathrm{v} 25 \mathrm{~mL}$ formaldehyde $(0.3 \mathrm{~mole})$ was added from addition funnel with constant stirring. It was stirred for $1 \mathrm{~h}$ at room temperature. Then the solution of $m$-cresol $(10.8 \mathrm{~g}, 0.1$ mole $)$ in $20 \mathrm{~mL}$ DMF was added from addition funnel at 
the rate of $2 \mathrm{~mL} / \mathrm{min}$. The mixture was heated on water bath at $100{ }^{\circ} \mathrm{C} \pm 6{ }^{\circ} \mathrm{C}$ temperature with constant stirring for about $2-4 \mathrm{~h}$ till soft jelly type material was obtained. The cured mass was then crushed to $20-50$ mesh size particles and it was washed with methanol and finally with hot double distilled water to removed unreacted monomers. The resin was dried in vacuum oven at $100{ }^{\circ} \mathrm{C}$. The yield of the reddish brown resin was $75 \%$.

\section{Apparatus and procedure}

The dry resin of 20-50 mesh size particles were used for characterization. Infrared spectra of the synthesized resin had been scanned in KBr pellets on "Shimadzu FTIR Spectrophotometer" model 8201PC. The elemental analysis was carried out on "Carlo Erba Elemental Analyzer" model 1160. The surface analysis was done using Scanning Electron Microscopy (Philips XL30, Japan) at $400 \mathrm{X}$ and $500 \mathrm{X}$ magnifications. The optical photograph was taken on "SZX-12 Olympus, Japan". The thermogram of the resin sample was taken on "Mettler TA 4000" at constant heating rate of $100{ }^{\circ} \mathrm{C} / \mathrm{min}$ in $\mathrm{N}_{2}$ atmosphere. The water swollen resin was regenerated with $0.1 \mathrm{M} \mathrm{HCl}$ to obtain its $\mathrm{H}^{+}$ form for further studies. The physico-chemical properties like $\%$ moisture content, $\%$ solid, true density, apparent density, void volume fraction, concentration of fixed ionogenic group, sodium exchange capacity, salt splitting and resin stability were studied according to literature methods $\mathrm{s}^{7,8}$. The results are shown in Table 1 . The ion exchange properties such as rate of metal ion exchange, effect of $\mathrm{pH}$ on metal ion exchange capacity, effect of metal ions concentration and distribution coefficient in tartaric acid media were also studied ${ }^{9}$. All experiments were carried out according to earlier methods ${ }^{10}$.A batch equilibration method was adopted for the determination of the metal ion uptake capacity of resin using different experimental variable such as metal ion concentration, $\mathrm{pH}$ and rate of exchange ${ }^{11,12}$.

Table 1. Physical properties of AFM resin.

\begin{tabular}{ll}
\hline Properties & Value (SD) \\
\hline$\%$ moisture & $8.6 \pm 0.5$ \\
$\%$ solid & $91.4 \pm 0.5$ \\
True density (dres), g/cm ${ }^{3}$ & $1.15 \pm 0.03$ \\
Apparent density (dcol), g/mL & $0.6848 \pm 0.0060$ \\
Void volume fraction & $0.4045 \pm 0.0050$ \\
Sodium exchange capacity, $\mathrm{mmol} / \mathrm{g}$ dry resin & $6.24 \pm 0.20$ \\
Concentration of fixed ionogenic group $\mathrm{mmol} / \mathrm{cm}^{3}$ & $6.5503 \pm 0.2000$ \\
Volume capacity, $\mathrm{mmol} / \mathrm{cm}^{3}$ & $3.71 \pm 0.05$ \\
\hline
\end{tabular}

\section{Result and Discussion}

\section{Characterization of AFM resin}

The important IR bands were observed at $3400 \mathrm{~cm}^{-1}$ due to $v(\mathrm{O}-\mathrm{H})$ of phenolic group and $v(\mathrm{~N}-\mathrm{H})$ of amino group, $2924 \mathrm{~cm}^{-1}$ due to $v(\mathrm{C}-\mathrm{H})$ methylene group, $1750 \mathrm{~cm}^{-1}$ exhibits $v(\mathrm{C}=\mathrm{O})$ of ketonic group of acid, $1615 \mathrm{~cm}^{-1}$ due to $\delta(\mathrm{N}-\mathrm{H})$ and $v(\mathrm{C}=\mathrm{C})$ of aromatic ring, $1380 \mathrm{~cm}^{-1}$ for $\delta(\mathrm{C}-\mathrm{H})$ of $\mathrm{Ar}-\mathrm{CH}_{3}, 1279 \mathrm{~cm}^{-1}$ for $v(\mathrm{C}-\mathrm{N})$ of $\mathrm{Ar}-\mathrm{NH}_{2}$ and primary amine, $1159 \mathrm{~cm}^{-1}$ due to $v(\mathrm{C}-\mathrm{O})$ of phenol, $854 \mathrm{~cm}^{-1}$ tetra substituted benzene ring. The FTIR spectral data matches with probable structure unit of the copolymerized monomers as shown in Scheme-1. 


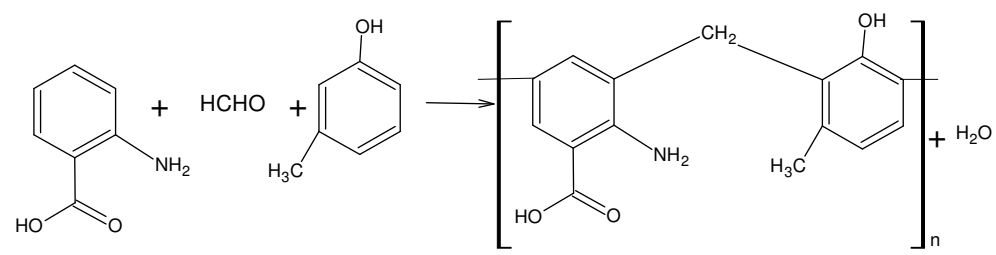

\section{Elemental Analysis}

Scheme -1

The results of elemental analysis are in good agreement with calculated values of $\% \mathrm{C}$, $\% \mathrm{H}$ and $\% \mathrm{~N}$. Theoretically calculated (\%) $70.0(\mathrm{C}) ; 5.8(\mathrm{H}) ;$ and $5.5(\mathrm{~N})$. Found $(\%)$ $70.4(\mathrm{C}) ; 5.5(\mathrm{H})$; and $5.8(\mathrm{~N})$.

\section{Scanning Electron Micrographs}

The morphology of resin exhibits growth of crystals from polymer solutions corresponding to the most prominent organization in polymers on a large scale such as in size of few millimeters of spherulites. The morphology of the resin polymer shows a fringed micelle model of the crystalline- amorphous structure. The fringes represent transition material between the crystalline and amorphous phases. The extent of crystalline character is dependent on the acidic nature of the monomer. This tends to draw attention away from the details of fine structure and gives little insight into the structure of large entities such as spherulites, which is shown in Figure 1 (a-400X, b- 500X). The higher magnification $500 \mathrm{X}$ (Figure $1 \mathrm{~b}$ ) shows coexistence of an appreciable amorphous fraction with few shallow pits. The white bar at the bottom of the SEM micrographs represented the scale.

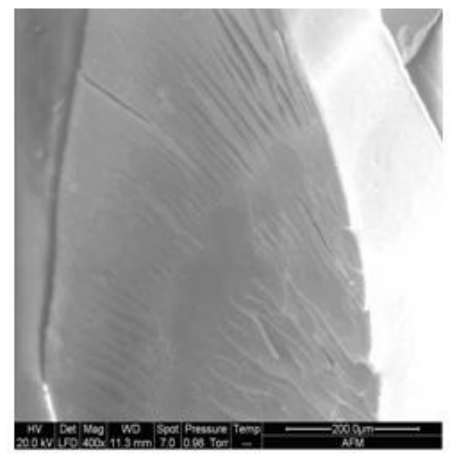

(a)

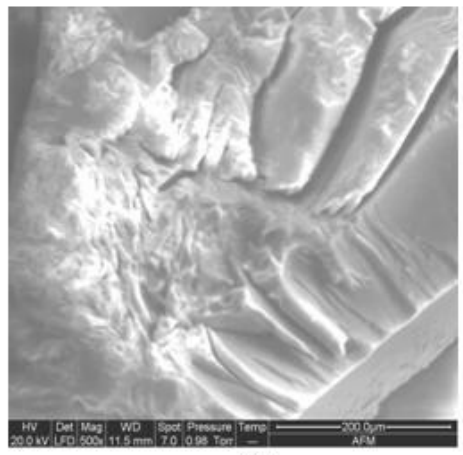

(b)

Figure 1. SEM photographs of AFM resin at different magnification $(a=400 X, b=500 X)$

\section{Optical photograph}

The optical photograph of synthesized resin is presented in Figure 2. It suggests that the resin appears to be reddish brown to black in color.

\section{Thermogravimetric Analysis (TGA)}

The thermogravimetric analysis has proved to be useful in evaluating kinetic parameters of various materials that provides valuable quantitative information regarding the stability of material. The result of TGA reveals that the degradation of AFM resin takes place between $410{ }^{\circ} \mathrm{C}$ to $560{ }^{\circ} \mathrm{C}$. It involves single step degradation with weight loss of $52.7 \%$. 
The maximum rate of weight loss is at $530{ }^{\circ} \mathrm{C}$. Broido ${ }^{13}$, Horowitz-Metzger ${ }^{14}$ and CoatsRedfern ${ }^{15}$ methods are used to estimate the Activation Energy (Ea) of thermal degradation. The values of Activation Energy calculated by all these methods are shown in Table 2. Intergal Produral Decomposition Temperature (IPDT) is calculated by Doyle's method ${ }^{16}$. IPDT expresses the overall thermal stability of the resin, which is $349^{\circ} \mathrm{C}$.

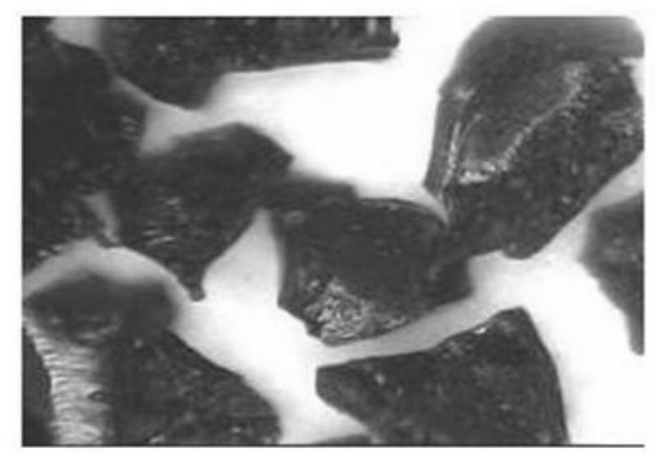

Figure 2. Optical photograph of AFM resin

Table 2. Thermodynamic parameters of AFM resin $\left[E_{a}(\mathrm{~kJ} / \mathrm{mol}), \mathrm{S}^{*}(\mathrm{~J} / \mathrm{Kmol}), \mathrm{H}^{*}\right.$ $(\mathrm{kJ} / \mathrm{mol})$ and $\left.\mathrm{G}^{*}(\mathrm{~kJ} / \mathrm{mol})\right]$.

\begin{tabular}{ccccccc}
\hline Step & Properties & $\begin{array}{c}\text { Broido } \\
\text { method }\end{array}$ & $\begin{array}{c}\text { Horowitz } \\
\text {-Metzger } \\
\text { method }\end{array}$ & $\begin{array}{c}\text { Order of } \\
\text { decomposition }\end{array}$ & $\begin{array}{c}\text { Coats- } \\
\text { Redfern } \\
\text { method }\end{array}$ & $\begin{array}{c}\text { IPDT } \\
{ }^{\circ} \mathrm{C}\end{array}$ \\
\hline \multirow{3}{*}{ Step-1 } & $\mathrm{E}_{\mathrm{a}}$ & 20.1 & 21.3 & & 17.32 & \\
& $\mathrm{~S}^{*}$ & -100.34 & -100.34 & 2 & -105.07 & 349 \\
& $\mathrm{H}^{*}$ & 14.42 & 15.62 & & 11.64 & \\
& $\mathrm{G}^{*}$ & 82.95 & 84.36 & & 83.40 & \\
\hline
\end{tabular}

The Activation Energy of AFM resin may be explained based on its macromolecular structure. In amphoteric (Anthranilic acid containing AFM resin) polymeric compounds, there are different types of interactions related to its backbone bonding and various groups present on the polymeric backbone. Since these intermolecular interactions depend on the nature of atoms and distance between them, the polymer strength depends on both these factors. The type of the group attached to the polymeric backbone can demonstrate the effect of distance between such macromolecules. AFM resin contains non-polar $-\mathrm{CH}_{3}$ group at meta position and it also contains bulky $-\mathrm{NH}_{2}$ group. Due to their repulsive force, sufficient rigid structure cannot be obtained. This will produce more amorphous character in the polymeric resin. Hence it exhibits lower Activation Energy of AFM resin such as $20.4 \mathrm{~K} \mathrm{~J} /$ mole compared to resorcinol containing amphoteric AFR resin ${ }^{10}$, which has $28.20 \mathrm{~K} \mathrm{~J} / \mathrm{mole}$.

The thermal degradation of AFM resin exhibits second order reaction ${ }^{15}$. The thermodynamic parameters such as Entropy change $\left(\mathrm{S}^{*}\right)$, Enthalpy $\left(\mathrm{H}^{*}\right)$ and Free Energy $\left(\mathrm{G}^{*}\right)$ for degradation was calculated by Coats-Redfern methods ${ }^{15}$, which is shown in Table 2. Lower negative value of $S^{*}$ suggested more randomization in structure of AFM resin. The positive value of $\mathrm{H}^{*}$ and $\mathrm{G}^{*}$ of synthesized resin suggests that the degradation process was endothermic and slower one. 


\section{Physico-chemical characteristics}

\section{Resin stability}

It was observed that up to 20 loadings and acid washing cycles, sodium ion exchange capacities and copper ion exchange capacities of reported resin did not change, which suggests that the resin exhibits appreciably better stability. Thus, reuse of the resin column is feasible. The resin is non-melting and insoluble in most of solvents.

\section{Rate of exchange for metal ions}

Ion exchange being inherently a stoichiometric process, any counter ion leaving ion exchanger is replaced by an equivalent amount of other counter ion under diffusion effect between solution and resin film surface. The deviations from stoichiometric behavior occur due to electrolyte sorption and adsorption, which cause change in co-ion content of the ion exchange. As the co-ion does not participate in ion exchange, it has little effect on the rate of exchange. Figure 3 shows the results of rate of exchange of metal ion on AFM resin. It is observed that half reaction time $\left(\mathrm{t}_{1 / 2}\right)$ for $\mathrm{Cu}$ (II) and $\mathrm{Ni}(\mathrm{II})$ is after 50 minutes, for $\mathrm{Zn}$ (II) is after 5 hours, for $\mathrm{Pb}$ (II) after 20 minutes while for $\mathrm{Cd}(\mathrm{II})$ after 2 hours. Faster rate of $\mathrm{t}_{1 / 2}$ was exhibited by $\mathrm{Cu}$ (II) than $\mathrm{Zn}$ (II). This is attributed to fact that the hydrated $\mathrm{Cu}$ (II) have smaller radii than hydrated $\mathrm{Zn}$ (II) and thus, have greater access to the surface. The rate of exchange for the post transition metal ions exhibits the reverse trend, for $\mathrm{Cd}(\mathrm{II})$ the rate of exchange is lower than that of $\mathrm{Pb}(\mathrm{II})$ because of the difference in $\mathrm{d}$ orbital.

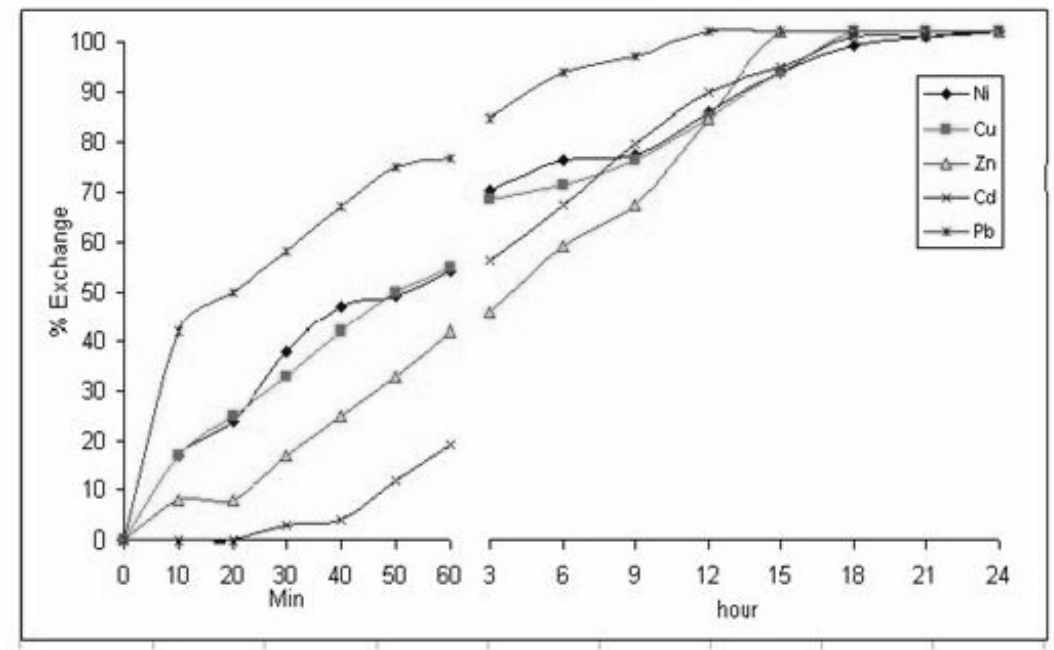

Figure 3. Rate of exchange for metal ions exchange capacity on AFM resin

\section{pH dependence of metal ion exchange capacity}

At specific conditions of $\mathrm{pH}$, resin is able to form chelating complexes with metal ions. At different $\mathrm{pH}$, exchange capacities of different metal ions have been studied with $0.05 \mathrm{M}$ concentration of each metal ion, which is shown in Figure 4. The maximum exchange capacity for $\mathrm{Cu}(\mathrm{II})$ and $\mathrm{Pb}$ (II) is found to be at $\mathrm{pH}$ 6.0. For $\mathrm{Ni}$ (II) it is at $\mathrm{pH} 4.0$ and for $\mathrm{Cd}(\mathrm{II})$ it is at $\mathrm{pH} 4.5$, while ion exchange capacity of $\mathrm{Zn}$ (II) is independent of $\mathrm{pH}$ in the range of $\mathrm{pH} 3.5$ to $\mathrm{pH}$ 6.5. The exchange capacity order is as follows: $\mathrm{Ni}$ (II) $>\mathrm{Cu}$ (II) $>$ $\mathrm{Cd}(\mathrm{II})>\mathrm{Zn}(\mathrm{II})>\mathrm{Pb}(\mathrm{II})$. 


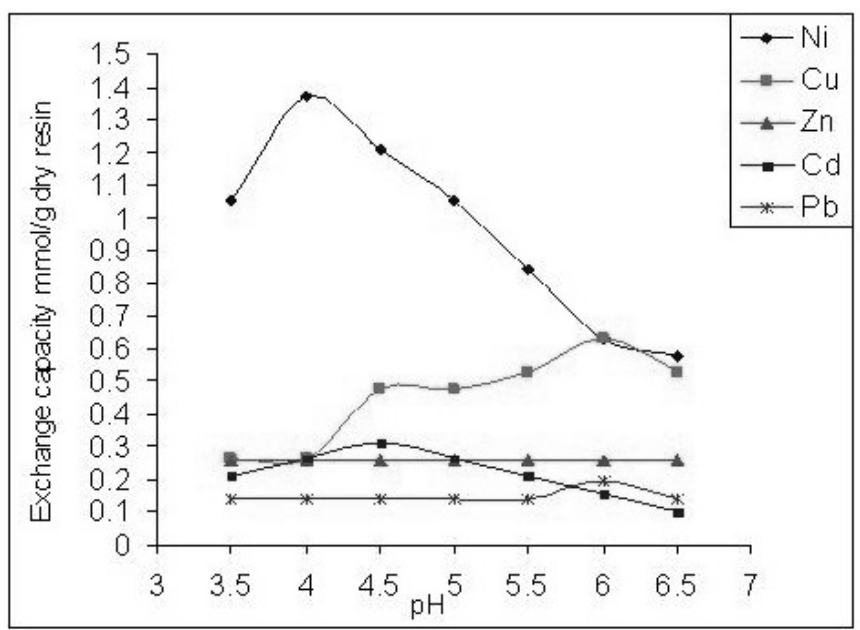

Figure 4. Effect of $\mathrm{pH}$ on metal ion exchange capacity on AFM resin

From the results it reveals that with decrease in atomic number the exchange capacity is increasing. In the case of $\mathrm{Cd}(\mathrm{II})$ and $\mathrm{Pb}$ (II) purely electrostatic factors are responsible. The ion exchange capacity of $\mathrm{Cd}(\mathrm{II})$ is lower owing to the large size of its hydrated ion than that of $\mathrm{Cu}$ (II). The steric influence of the methyl group and amino group in AFM resin is probably responsible for their observed low binding capacities for various metal ions. Thus, the interaction of this resin material with various metal ions in an aqueous environment may largely limit the binding sites, which are suitably, disposed in a conformationally favorable manner on surface layers.

\section{Effect of concentration of metal ions on metal ion exchange capacity}

The study of the effect of concentration of metal ion shows that the uptake of metal ion by the resin increases in proportion to the concentration of metal ion in solution. The saturation occurred at about $0.25 \mathrm{M}$ to $0.40 \mathrm{M}$ concentration of metal salt solution. This may be due to different selectivity at various concentrations which is shown in Figure 5. The role of physical core structure of the resin is significant in the uptake of different metal ions by the resin copolymer.

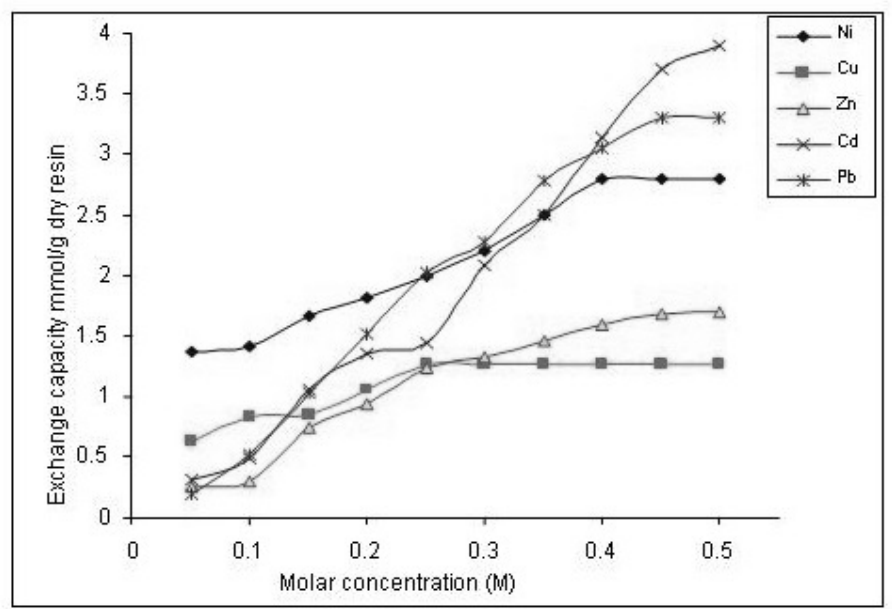

Figure 5. Effect of concentration on metal ion exchange capacity on AFM resin 
Effect of electrolyte concentration and $\mathrm{pH}$ on distribution coefficient $\left(K_{d}\right)$ of metal ions

Batch equilibrium method is more fruitful to determine distribution coefficient $\left(\mathrm{K}_{\mathrm{d}}\right)$ for the metal ions as a function of tartaric acid concentration. The distribution of the different metal ions as the function of $\mathrm{pH}$ and concentration of electrolyte solution (tartaric acid) are presented in Table 3. For heavy metal ions, $\mathrm{Pb}$ (II) showed higher $\mathrm{K}_{\mathrm{d}}$ values, while $\mathrm{Cd}$ (II) showed lower $\mathrm{K}_{\mathrm{d}}$. The value of distribution ratio for given $\mathrm{pH}$ and for a given concentration of electrolyte depends upon the nature and the stability of a chelate formation for particular metal ion. The data of $K_{d}$ show a random trend in certain case ${ }^{10}$. This may be due to amphoteric nature of the AFM resin. Table 3 shows that the reported resin provides better selectivity for one metal ion in presence of the other metal ions. Distribution coefficients were measured for all metal ions as a function of tartaric acid concentration and prediction of whether a separation for a given pair of metal ions is possible by comparing their $\mathrm{K}_{\mathrm{d}}$ values.

\section{Chromatographic column separation of Binary mixture}

The superior selectivity towards multivalent cations exhibited by chelating resin has been demonstrated in column experiments by using $K_{d}$ values. The values of the $K_{d}$ are shown in Table 3. An ideal situation would be such that one $K_{d}$ values is ten times greater than the $K_{d}$ value for other ion, while the other approaches zero. The first eluting fractions of tartaric acid carry one metal ion which has a smaller $\mathrm{K}_{\mathrm{d}}$ values. The second metal ion eluted by changing the tartaric acid concentration to a level that produced a high $\mathrm{K}_{\mathrm{d}}$ values.

For the separation of binary mixture, $2 \mathrm{~mL}$ of $5 \mathrm{mg} / \mathrm{mL}$ of each metal ion solution was taken. The chelating resin in $\mathrm{H}^{+}$form was packed into a chromatographic column to form a compact column bed $\sim 15 \mathrm{~cm}$ height and $0.4 \mathrm{~cm}$ diameter. The solution is allowed to flow through automatic fraction collectors for the continuous determination of metal ion separation. Each fraction was analyzed individually for its constituent metal ion by complexometric titration. These reading are then plotted against volume of eluate.

Figure 6 shows the separation of $\mathrm{Pb}$ (II) from $\mathrm{Cd}(\mathrm{II}) . \mathrm{Pb}$ (II) can be removed by passing a solution of the acetate salt at $\mathrm{pH} 3.5$ and $1.0 \mathrm{M}$ tartaric acid through a column of the resin; $\mathrm{Cd}$ (II) does not form the complex with resin at $\mathrm{pH} 3.5$ and later $\mathrm{Cd}$ (II) was eluted with $0.3 \mathrm{M}$ tartaric acid of $\mathrm{pH}-3.0$. Recovery of $\mathrm{Pb}(\mathrm{II})$ and $\mathrm{Cd}(\mathrm{II})$ are found to be $94 \%$ and $87 \%$ respectively.

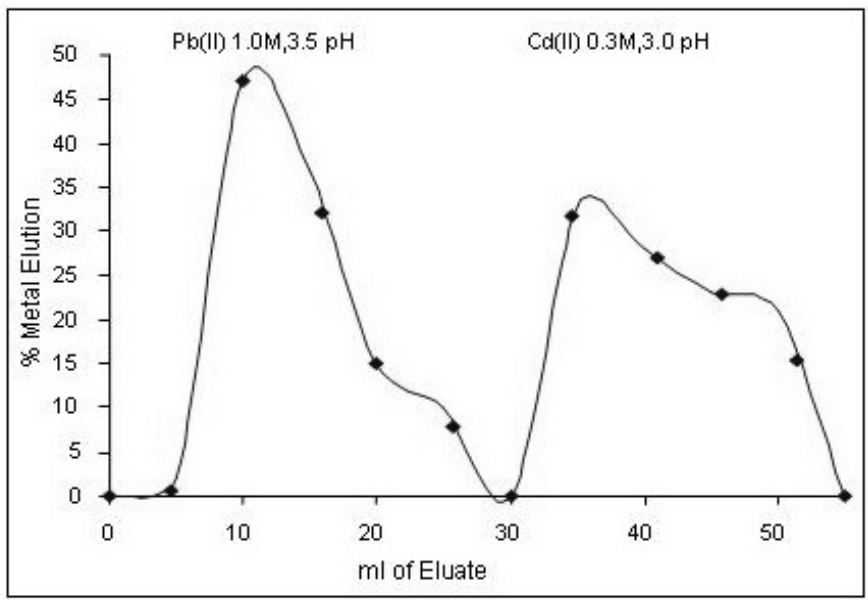

Figure 6. Separation of $\mathrm{Pb}(\mathrm{II})$ and $\mathrm{Cd}(\mathrm{II})$ on $\mathrm{AFM}$ resin 
In the case of separation of $\mathrm{Pb}(\mathrm{II})$ from $\mathrm{Zn}(\mathrm{II})$, chelated $\mathrm{Pb}$ (II) and $\mathrm{Zn}(\mathrm{II})$ were separated by selective sorption with $0.1 \mathrm{M}$ tartaric acid solution of $\mathrm{pH}$ 5.0. First few fractions contain only $\mathrm{Pb}$ (II) and later by $0.3 \mathrm{M}$ tartaric acid of $\mathrm{pH} 3.0$ only $\mathrm{Zn}$ (II) was eluted. Recovery of $\mathrm{Pb}$ (II) was found to be $92 \%$, while for $\mathrm{Zn}$ (II) it is $83 \%$. No cross contamination was observed for this separation. Result is given in Figure 7.

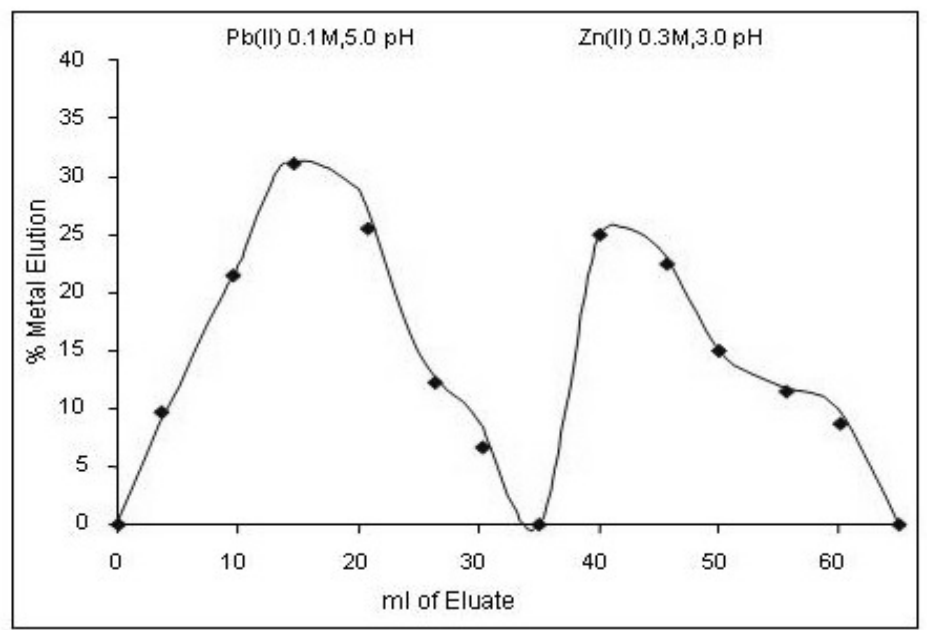

Figure 7. Separation of $\mathrm{Pb}(\mathrm{II})$ and $\mathrm{Zn}(\mathrm{II})$ on $\mathrm{AFM}$ resin

In the case of separation of $\mathrm{Zn}$ (II) from $\mathrm{Cu}$ (II), $\mathrm{Zn}$ (II) was eluted with $0.2 \mathrm{M}$ tartaric acid at $\mathrm{pH}-6.0$. Few fractions contain only $\mathrm{Zn}(\mathrm{II})$, later $\mathrm{Cu}(\mathrm{II})$ was eluted with $1.0 \mathrm{M}$ tartaric acid of pH-3.0. Recovery of $\mathrm{Cu}(\mathrm{II})$ was found to be $95 \%$ while $\mathrm{Zn}$ (II) was found to be $91 \%$. Result is given in Figure 8.

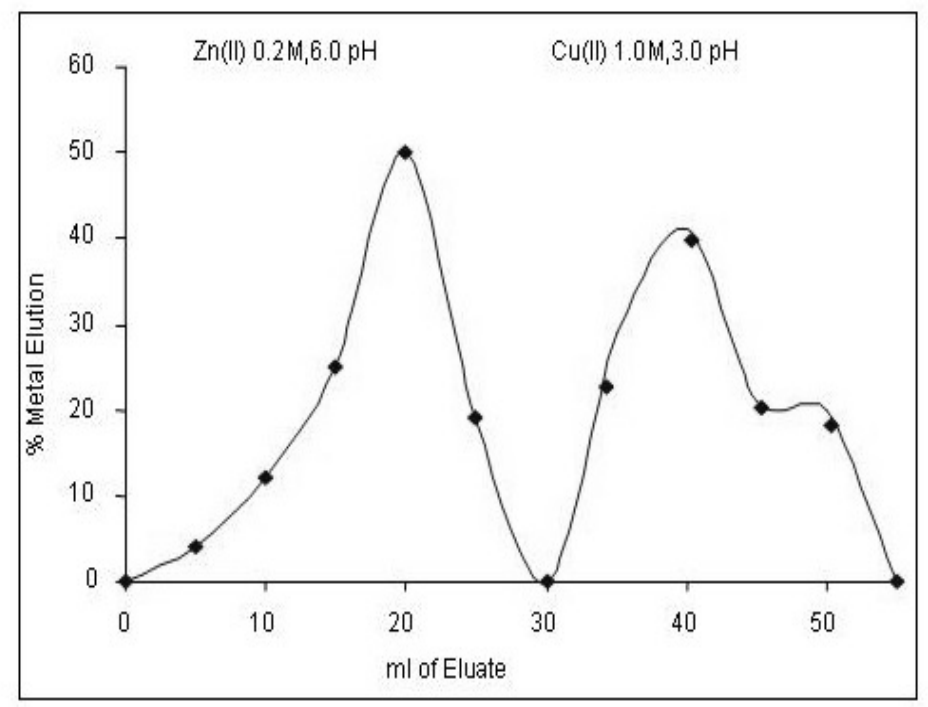

Figure 8. Separation of $\mathrm{Zn}(\mathrm{II})$ and $\mathrm{Cu}(\mathrm{II})$ on $\mathrm{AFM}$ resin 
Table 3. $\mathrm{K}_{\mathrm{d}}$ values of metal ions on AFM resin in tartaric acid media at different $\mathrm{pH}$.

\begin{tabular}{|c|c|c|c|c|c|c|}
\hline \multirow{2}{*}{$\begin{array}{l}\text { Metal } \\
\text { ion }\end{array}$} & \multirow{2}{*}{$\begin{array}{c}\text { Tartaric } \\
\text { acid Conc, } \\
\text { M }\end{array}$} & \multicolumn{5}{|c|}{$\mathrm{K}_{\mathrm{d}}$ values at different $\mathrm{pH}$} \\
\hline & & 3.0 & 3.5 & 4.0 & 5.0 & 6.0 \\
\hline \multirow{5}{*}{$\mathrm{Ni}(\mathrm{II})$} & 0.1 & 27.0 & 45.0 & 45.0 & 27.9 & 45.3 \\
\hline & 0.2 & 69.0 & 27.0 & 27.0 & 9.0 & 9.0 \\
\hline & 0.3 & 27.0 & 20.6 & 20.0 & 9.0 & 48.0 \\
\hline & 0.5 & 150.0 & 60.3 & 39.6 & - & 9.0 \\
\hline & 1.0 & 180.0 & 75.1 & 21.0 & - & - \\
\hline \multirow{5}{*}{$\mathrm{Cu}(\mathrm{II})$} & 0.1 & 90.0 & 90.5 & 54.0 & 39.0 & 150.0 \\
\hline & 0.2 & 150.0 & 210.3 & 370.0 & - & 103.5 \\
\hline & 0.3 & 90.0 & 215.9 & 51.3 & 100.2 & 75.8 \\
\hline & 0.5 & - & 75.8 & - & 132.0 & - \\
\hline & 1.0 & - & - & - & - & - \\
\hline \multirow{5}{*}{$\mathrm{Zn}(\mathrm{II})$} & 0.1 & - & 75.6 & 90.0 & 71.0 & 99.5 \\
\hline & 0.2 & 99.5 & 75.0 & 100.0 & 90.0 & - \\
\hline & 0.3 & 51.6 & 45.0 & 85.6 & 30.5 & 60.3 \\
\hline & 0.5 & 30.4 & 18.2 & 45.0 & 12.3 & - \\
\hline & 1.0 & 90.5 & 55.0 & 24.0 & 24.5 & 51.2 \\
\hline \multirow{5}{*}{$\mathrm{Cd}(\mathrm{II})$} & 0.1 & 200.0 & 75.0 & 18.0 & 66.8 & 60.0 \\
\hline & 0.2 & 75.0 & 105.6 & 6.0 & - & - \\
\hline & 0.3 & 150.0 & 15.0 & 48.3 & 70.3 & - \\
\hline & 0.5 & 90.0 & 33.5 & 48.3 & 18.2 & - \\
\hline & 1.0 & 100.2 & 100.2 & 12.0 & 75.6 & - \\
\hline \multirow{5}{*}{$\mathrm{Pb}(\mathrm{II})$} & 0.1 & 90.6 & 70.6 & 100.2 & - & 60.3 \\
\hline & 0.2 & 150.0 & 240.0 & 200.3 & 140.0 & 130.0 \\
\hline & 0.3 & 600.9 & 350.6 & 214.3 & - & 60.0 \\
\hline & 0.5 & - & 300.0 & 90.5 & 33.6 & 75.5 \\
\hline & 1.0 & 33.0 & - & 60.0 & 15.2 & 60.0 \\
\hline
\end{tabular}

\section{Conclusions}

The ion exchange resin AFM was synthesized and characterized by instrumental methods. TG data reveals that the resin shows single step degradation and moderate thermal stability. The ion exchange capacity for $\mathrm{Pb}(\mathrm{II})$ is lowest, which is due to larger hydrated radius. The kinetic ion exchange rate was fastest $\left(\mathrm{t}_{1 / 2}<22 \mathrm{~min}\right)$ for $\mathrm{Pb}$ (II). The binding capacity of some metal ions by the resin was carried out by the batch technique. The exchange capacities of metal ions by the resin were $\mathrm{pH}$ dependent except $\mathrm{Zn}$ (II). From the results of distribution coefficients it can be observed that $\mathrm{Pb}$ (II) has higher $\mathrm{K}_{\mathrm{d}}$ value. Due to considerable difference in the exchange capacity at different $\mathrm{pH}$ and media of electrolyte, the rate of metal uptake and distribution ratios at equilibrium, it is possible to use resin for separation of particular metal ions from their admixture.

\section{Acknowledgement}

We are thankful to Head, IIT, Mumbai for providing SEM. We are also thankful to Head, CDRI, Lucknow for providing spectral facility. We are thankful to Head, SICRAT, Vallabh Vidhyanagar, for providing Thermal Analysis. 


\section{References}

1. Min-jane chen and chuen-ying liu, J. Chin. Chem. Soc. 1999, 46 (5), 8.

2. Dutta S and Das A, Ind J Chemical Technology. 2005, 12,139.

3. Lutfor M.R and Silong S, European Polymer Journal, 2000, 36, 2105.

4. $\quad$ Patel S. A., Shah B. S and Patel R.M, Iranian Polymer Journal, 2004, 13 (6), 445.

5. Ebraheem K.A.K., Al-duhan J.A. and Hamdi S T, European Polymer Journal. 1985, 21, 97.

6. Das S C, J. Indian Chem. Soc. 2000, 77, 69.

7. Vogel A. Textbook of Qualitative Chemical Analysis, $5^{\text {th }}$ Ed., Longman group, UK. 1989.

8. Helfferich F, Ion Exchange, McGraw-Hills, New York, 1962.

9. Kunnin R, Ion Exchange Resin, Wiley, London, 1958.

10. Shah B A, Shah A V and Shah P M, Iranian Polymer Journal. 2006, 15(10), 809.

11. DeGeiso R C, Donarnuma L G and Tomic E A, Anal. Chem, 1962, 34, 845. Chem. Abstr, 1962, 57,6653c.

12. Donarnuma L G, U.S. Pat. 3052,515, 1962; Chem. Abst. 1962, 57, 13467a.

13. Broido A, J. Polym. Sci., 1969, 2A, 1761.

14. Horowitz H H and Metzger G, Anal. Chem., 1963, 35, 1464.

15. Coats A W, Redfern J P, Nature, 1964, 201, 68.

16. Doyle C.D, Anal. Chem., 1961, 33, 77. 


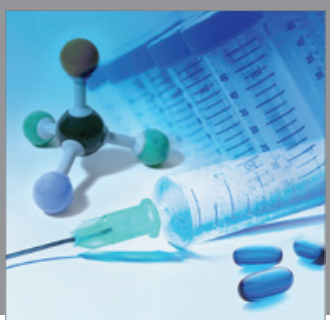

International Journal of

Medicinal Chemistry

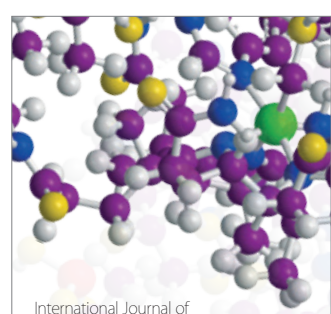

Carbohydrate Chemistry

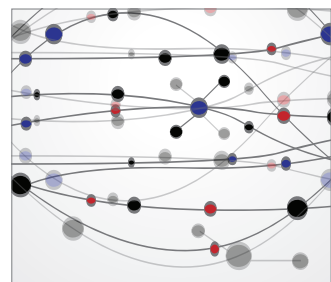

The Scientific World Journal
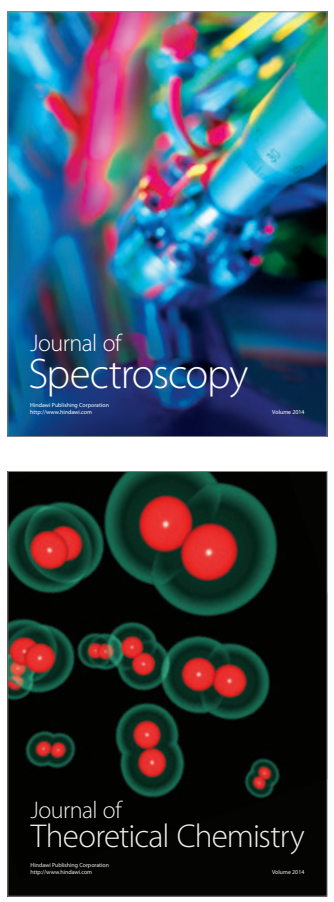
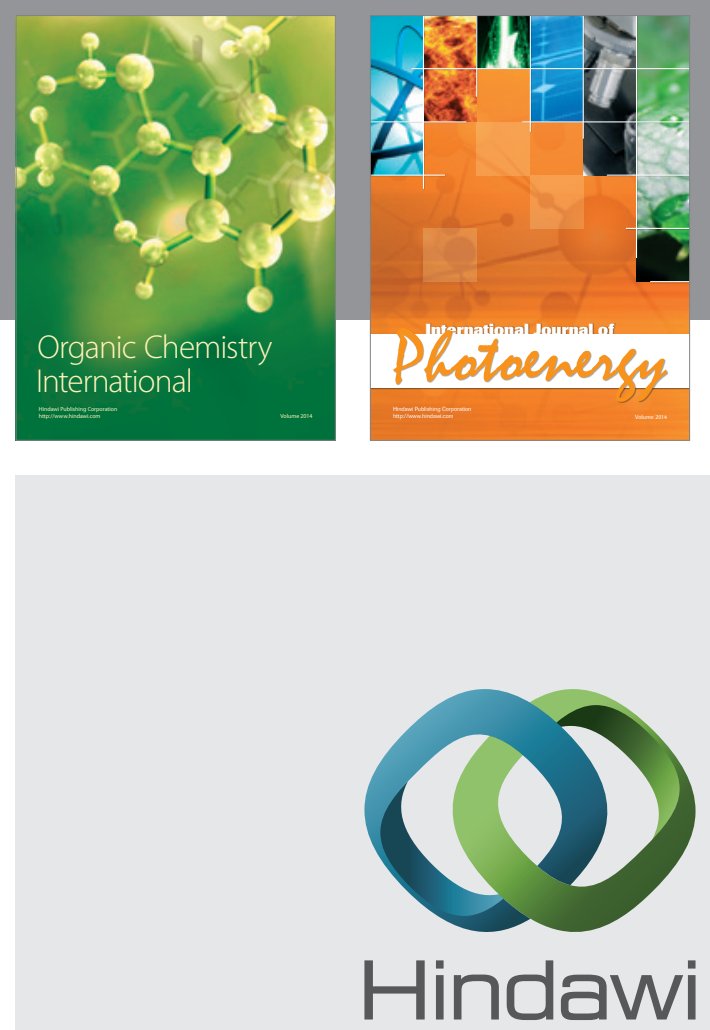

Submit your manuscripts at

http://www.hindawi.com
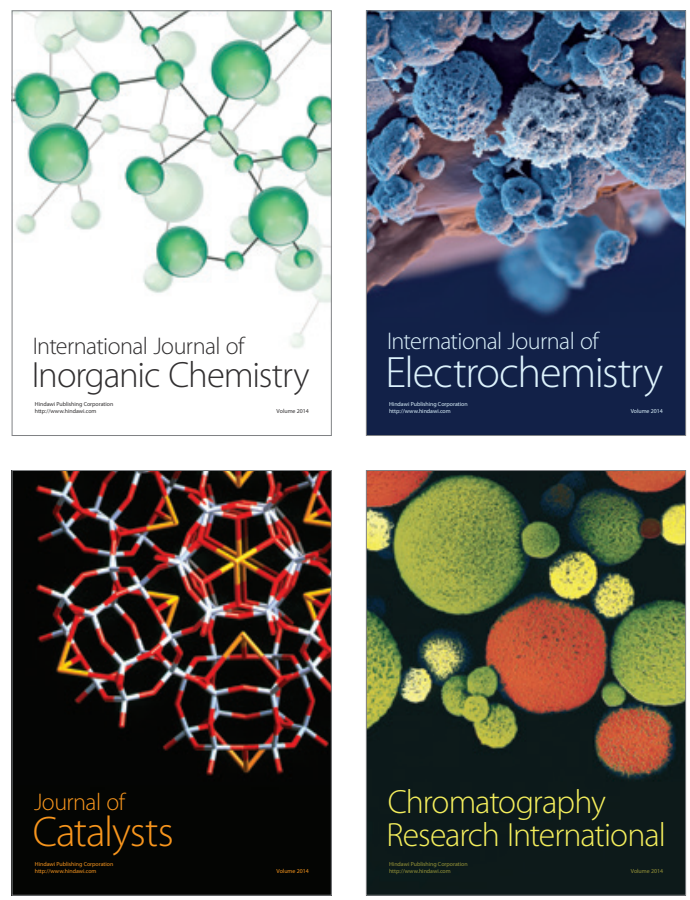
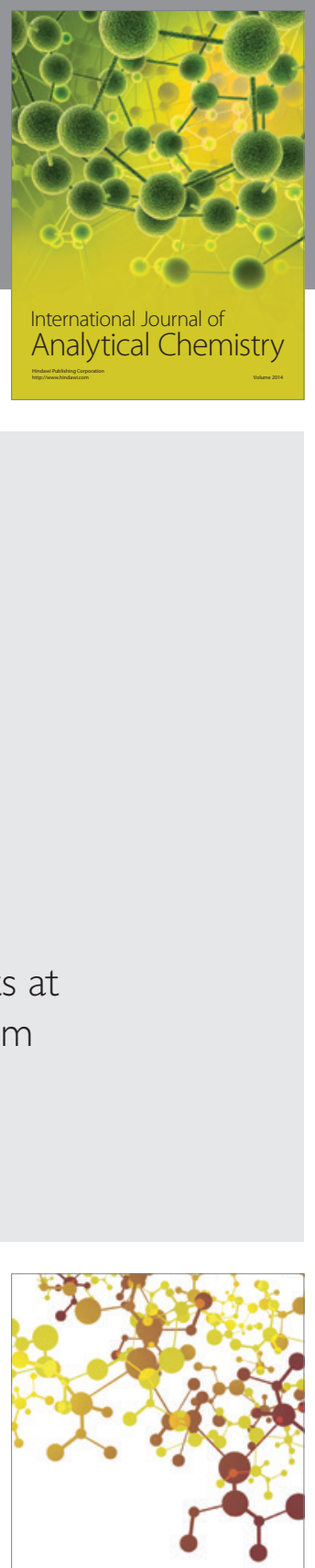

Journal of

Applied Chemistry
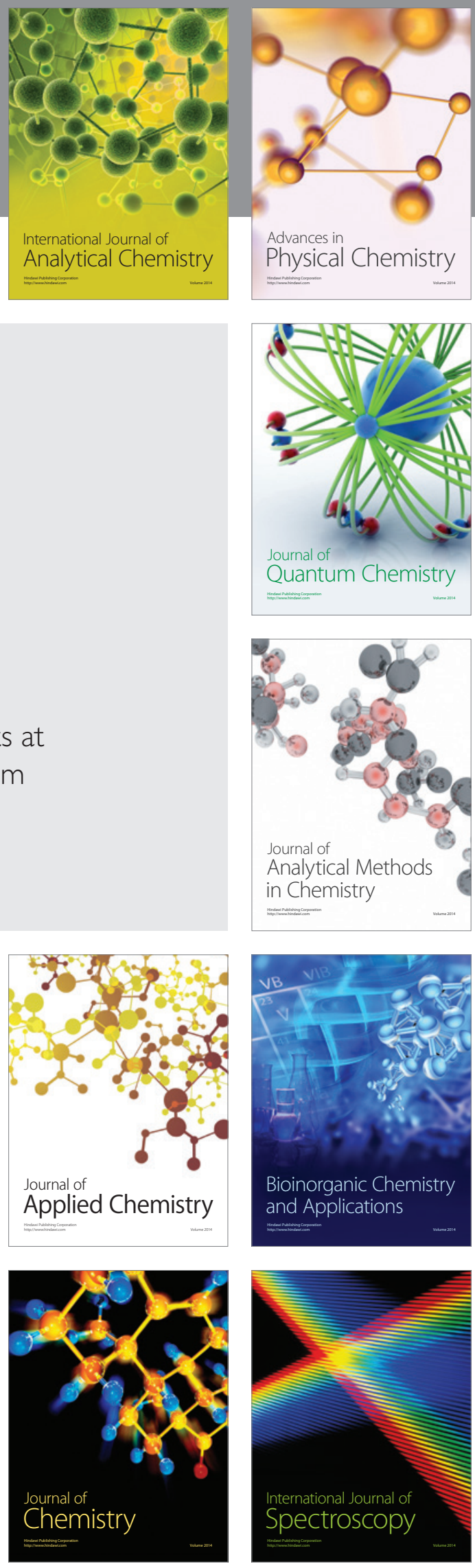